\title{
Mobilities of Organic Compounds in Reconstituted Cuticular Wax of Barley Leaves: Effects of Monodisperse Alcohol Ethoxylates on Diffusion of Pentachlorophenol and Tetracosanoic Acid
}

\author{
Lukas Schreiber, ${ }^{a *}$ Markus Riederer ${ }^{a} \&$ Karl Schorn ${ }^{b}$ \\ a Julius-von-Sachs-Institut für Biowissenschaften, Lehrstuhl für Botanik II, Universität Würzburg, \\ Mittlerer Dallenbergweg 64, D-97082 Würzburg, Germany \\ ${ }^{b}$ Max-Planck-Institut für Biophysikalische Chemie, Abteilung Spektroskopie, Am Faßberg, \\ D-37077 Göttingen, Germany
}

(Received 11 July 1995; revised version received 29 February 1996; accepted 15 April 1996)

\begin{abstract}
Effects of monodisperse alcohol ethoxylates on mobilities of ${ }^{14} \mathrm{C}$ labelled pentachlorophenol (PCP) and tetracosanoic acid $\left(\mathrm{C}_{24} \mathrm{AC}\right)$ in reconstituted cuticular wax of barley leaves were measured. Depending on the respective alcohol ethoxylate investigated, the diffusion coefficient $(D)$ of PCP in barley wax was increased by factors ranging from $3 \cdot 3$ to $19 \cdot 6$, whereas $D$ of $C_{24} \mathrm{AC}$, was increased by factors varying between 22 and 315 . In order to analyse the relationship between the concentration of surfactants in the wax and their effects on $D$, the amounts of alcohol ethoxylates dissolved in the wax at equilibrium with external concentrations well above the critical micelle concentration (CMC) were determined. Wax/water partition coefficients $\left(K_{w w}\right)$ of the alcohol ethoxylates were about one order of magnitude lower than cuticle/water partition coefficients $\left(K_{\mathrm{cw}}\right)$, which is a consequence of the semi-crystalline structure of the wax compared with amorphous cutin. Correlations between effects on $D$ and maximum amounts of alcohol ethoxylates dissolved in the wax were obtained indicating an unspecific wax/surfactant interaction. This was solely dependent on the amount of surfactant sorbed to the wax, leading to increased mobilities of pesticides in the wax. Applying ESR-spectroscopy, which gave an insight into the molecular structure of the wax, supported this interpretation of an unspecific plasticising effect of the alcohol ethoxylates on the molecular structure of the wax. The results obtained in this study are in good accordance with the results obtained in a recent study investigating the effects of the same group of alcohol ethoxylates on mobilities of pesticides in isolated, but intact, cuticular membranes of Citrus. This demonstrates that the investigation of isolated and subsequently reconstituted cuticular wax is a useful model system analysing the mechanisms of the surfactant interaction with the transport-limiting barrier of plant cuticles.
\end{abstract}

Key words: cuticular wax, diffusion, foliar uptake, plant cuticle, surfactant, transport

* To whom correspondence should be addressed. 


\section{INTRODUCTION}

Many plant-protecting chemicals, sprayed onto leaf surfaces, have to diffuse across a transport-limiting barrier, the plant cuticle, in order to reach their site of action. ${ }^{1}$ Plant cuticles, forming the interface between leaf and atmosphere, are composite membranes consisting of cutin and cuticular wax. ${ }^{2,3}$ Whereas cutin establishes an amorphous three-dimensional polymer network, ${ }^{4}$ cuticular wax is deposited into the outer region and to the outer surface of the cutin polymer. ${ }^{5,6}$ Due to its semicrystalline nature, it is essentially the cuticular wax that forms the transport-limiting barrier of the intact plant cuticle. ${ }^{7-10}$ In order to obtain a more fundamental and mechanistic understanding of this waxy transport barrier, an experimental system has been developed simulating cuticular transport properties with isolated and subsequently reconstituted cuticular wax. ${ }^{1-13}$

Surfactants are widely used as adjuvants for agrochemicals. Important reasons for their use are increased solubility of the active ingredient in the spray solution and improved wetting, spreading and adhesion of the spray droplets on leaf surfaces. ${ }^{14}$ Furthermore, it has been shown that surfactants have the ability to increase cuticular permeability for penetrating substances, although the mechanism of this is not clear. ${ }^{15-20} \mathrm{~A}$ study investigating the effects of monodisperse alcohol ethoxylates on the mobility of 2,4-D in isolated cuticles suggested that surfactants have to sorb to the transportlimiting wax barrier of cuticles in order to increase their permeability. ${ }^{21-22}$

Therefore, a study of the transport properties of isolated cuticular wax should provide information relevant to the understanding of wax/surfactant interactions. In a first attempt, the interaction of one monodisperse alcohol ethoxylate with reconstituted barley wax was investigated, showing that it is possible to simulate surfactant/cuticle interactions investigating reconstituted cuticular wax. ${ }^{12}$ The present work investigates surfactant/wax interactions including an increased number of monodisperse alcohol ethoxylates and some further experimental procedures, which help to obtain a better understanding of the increase of cuticular permeability by surfactants.

\section{MATERIALS AND METHODS}

\subsection{Plant materials}

Leaves of four- to six-week-old barley plants (Hordeum vulgare L. cv. Magie), grown in growth chambers $[16 \mathrm{~h}$ light at $500-800 \mu \mathrm{mol} \mathrm{m}^{-2} \mathrm{~s}^{-1}$ PAR (photosynthetic active radiation), $25^{\circ} \mathrm{C}$ and $50 \%$ R.H. (relative humidity); $15^{\circ} \mathrm{C}$ and $90 \%$ R.H. during the dark], were sampled for the experiments. As described previously, cuticular wax was extracted by immersing the leaves for 1-3 $\mathrm{s}$ in chloroform at room temperature. ${ }^{11}$ Extracts were filtered twice and the solvent volume was reduced to give a final wax concentration of about $50 \mathrm{mg} \mathrm{ml}^{-1}$. Wax solutions prepared in this way were stored at $-18^{\circ} \mathrm{C}$ until they were used in the experiments.

\subsection{Chemicals and analytical procedures}

Monodisperse alcohol ethoxylates used in the experiments (Table 1) were obtained from Fluka (Neu-Ulm, Germany). Chemical purity of the alcohol ethoxylates was better than $97 \%$ (own determination by GCanalysis). ${ }^{14} \mathrm{C}$-labelled pentachlorophenol (PCP; specific radioactivity: $155 \mathrm{GBq} \mathrm{mol}^{-1}$ ) was obtained from Sigma (Deisenhofen, Germany) and ${ }^{14} \mathrm{C}$-labelled tetracosanoic acid $\left(\mathrm{C}_{24} \mathrm{AC}\right.$; specific radioactivity: $1728 \mathrm{GBq}$ $\mathrm{mol}^{-1}$ ) was purchased at CEA (Grenoble, France). Radiochemical purities of the ${ }^{14} \mathrm{C}$-labelled compounds were better than $98 \%$ (own determination by radioTLC). The spin probe used in the electron spin resonance (ESR) studies was 5-doxyl stearic acid (5-SASL) containing the nitroxyl-group at carbon atom 5 . The

TABLE 1

Abbreviations, Molecular Weights (MW) and Molar Volumes (MV) of the Eight Alcohol Ethoxylates Investigated in This Study

\begin{tabular}{llcc}
\hline \multicolumn{1}{c}{ Compound $^{a}$} & Abbreviation & $M W(\mathrm{~g})$ & $M V\left(\mathrm{~cm}^{3} \mathrm{~mol}^{-1}\right)^{b}$ \\
\hline Diethylene glycol monobutyl ether & $\mathrm{C}_{4} \mathrm{E}_{2}$ & $162 \cdot 23$ & $141 \cdot 19$ \\
Triethylene glycol monohexyl ether & $\mathrm{C}_{6} \mathrm{E}_{3}$ & 234.34 & 203.42 \\
Tetraethylene glycol monooctyl ether & $\mathrm{C}_{8} \mathrm{E}_{4}$ & 306.45 & 265.65 \\
Pentaethylene glycol monodecyl ether & $\mathrm{C}_{10} \mathrm{E}_{5}$ & 378.56 & 327.88 \\
Hexaethylene glycol monododecyl ether & $\mathrm{C}_{12} \mathrm{E}_{6}$ & 450.66 & 390.11 \\
Octaethylene glycol monododecyl ether & $\mathrm{C}_{12} \mathrm{E}_{8}$ & $538 \cdot 77$ & 458.21 \\
Heptaethylene glycol monotetradecyl ether & $\mathrm{C}_{14} \mathrm{E}_{7}$ & $522 \cdot 77$ & 452.34 \\
Octaethylene glycol monohexadecyl ether & $\mathrm{C}_{16} \mathrm{E}_{8}$ & 594.88 & 514.57 \\
\hline
\end{tabular}

${ }^{a}$ Source: Fluka (Neu-Ulm, Germany).

${ }^{b}$ Calculated according to Abraham and McGowan. ${ }^{33}$ 
spin probe, which was obtained from Sigma (Deisenhofen, Germany), had a chemical purity of $99 \%$.

Radioactivity was measured by liquid scintillation counting (TRI Carb 2000, Canberra Packard, Frankfurt, Germany) adding an adequate amount of scintillation cocktail (Ultima Gold XR, Canberra Packard, Frankfurt, Germany) to the samples. Analysis of nonradioactive alcohol ethoxylates sorbed to barley wax was carried out by capillary gas chromatography (GC) equipped with on-column injectors and flame ionisation detectors (HP 5890 II, Hewlett-Packard, Millville, NJ, USA) as described previously. ${ }^{23}$ Specific correction factors were determined for each homologue.

\subsection{Preparation of wax samples}

Wax samples used in the experiments were prepared as described previously. ${ }^{11}$ In short, aluminium discs $\left(100 \mathrm{~mm}^{2}\right.$ surface area and $25 \mu \mathrm{m}$ thickness) were immersed in the chloroform solutions so that, after evaporation of the solvent, the discs were covered with a homogeneous layer of wax. In order to improve the adhesion of the wax to the surface of the discs, they were heated to $100^{\circ} \mathrm{C}$ for $5 \mathrm{~min}$. The amount of wax covering the aluminium surface was determined by weight using an electronic microbalance (Sartorius, Göttingen, Germany; accuracy: $\pm 1 \mu \mathrm{g}$ ). The average thickness of investigated wax layers was $2 \cdot 2( \pm 1) \mu \mathrm{m}$, using a wax density of $0.9 \mathrm{~g} \mathrm{~cm}^{-3}$ for the calculation of the thickness. ${ }^{24}$

Wax samples, prepared according to the above method, will be referred to as 'non-radioactive' wax samples and were used for investigating the sorption of alcohol ethoxylates to barley wax. In addition, 'radioactive' wax samples were prepared by adding a defined amount of a ${ }^{14} \mathrm{C}$-labelled compound (PCP or $\mathrm{C}_{24} \mathrm{AC}$ ) to the chloroform/wax solutions prior to recrystallisation and heating of the wax. 'Radioactive' wax samples were used for investigating the effects of the different alcohol ethoxylates on the diffusion of the ${ }^{14} \mathrm{C}$ labelled compounds in recrystallised barley wax.

\subsection{Determination of alcohol ethoxylate sorption in barley wax and calculation of wax/water partition coefficients}

Three 'non-radioactive' wax samples were incubated in $25-\mathrm{ml}$ glass vials containing an aqueous solution of the respective alcohol ethoxylates three to 25 times above their CMC (Conc; Table 2). As only small amounts of substance were sorbed in wax after equilibration, the large external aqueous volume and the relatively high surfactant concentration guaranteed that the concentration of monomeric surfactant molecules in the external aqueous solution remained nearly constant during the course of the experiment.
Equilibrium sorption of the alcohol ethoxylates between the wax samples and the external aqueous solutions was established after $24 \mathrm{~h}$. Wax samples were removed from the surfactant solutions, dipped for a few seconds into deionised water to remove superficially adhering alcohol ethoxylate and blotted carefully with a cellulose tissue to remove adhering water. Each wax sample was extracted with chloroform $(1 \mathrm{ml} ; 30 \mathrm{~min}$; $70^{\circ} \mathrm{C}$ ), the aluminium disc removed and the chloroform evaporated. The residue was treated at $70^{\circ} \mathrm{C}$ with pyridine $(5 \mu \mathrm{l})$ and $N, N$-bis-trimethylsilyltrifluoroacetamide (BSTFA; $5 \mu$; Machery-Nagel, Düren, Germany), which converts the free hydroxyl and carboxyl groups into their trimethylsilyl ethers and esters, respectively. Finally, samples were redissolved in chloroform containing a defined amount of hexacosan-1-ol (Fluka, Neu-Ulm, Germany) as internal standard. One microlitre of each sample was analysed by capillary gas chromatography (HP 5890 II, Hewlett-Packard, Millville, NJ, USA). Peaks of the respective alcohol ethoxylates, which could clearly be separated in the chromatogram from the peaks of the wax constituents, were quantified by internal standardisation using hexacosan-1-ol.

Wax/water partition coefficients of the alcohol ethoxylates were calculated according to:

$$
K_{w w}=\frac{M_{\text {wax }} / m_{\text {wax }}}{M_{\text {water }} / m_{\text {water }}}
$$

$M$ represents the amount of the investigated substance $(\mathrm{mol})$ in wax and water at equilibrium sorption, and $m$ (kg) represents the mass of the two compartments wax and water, respectively.

\subsection{Desorption of ${ }^{14} \mathrm{C}$-labelled $\mathrm{PCP}$ and $\mathrm{C}_{24} \mathrm{AC}$ from barley wax and calculation of diffusion coefficients}

Desorption experiments were carried out by incubating single 'radioactive' wax samples into 5-ml glass vials containing the aqueous desorption medium. Vials were closed with screw caps and rotated $\left(60 \mathrm{rev} \mathrm{min}^{-1}\right)$ in the dark at $25^{\circ} \mathrm{C}$. After defined periods of time, desorption medium in each vial was replaced by fresh solution and radioactivity was determined by liquid scintillation counting of the sampled desorption solution. In a first set of experiments, desorption kinetics (relative amounts desorbed versus time) of the two ${ }^{14} \mathrm{C}$-labelled compounds $\mathrm{PCP}$ and $\mathrm{C}_{24} \mathrm{AC}$ were determined using borate buffer ( $\left.\mathrm{pH} 9.0 ; 10^{-2} \mathrm{M}\right)$, which is an inert desorption medium with no effect on wax properties. ${ }^{12}$

Desorption kinetics could be linearised up to $50 \%$ desorption, plotting the relative amounts desorbed from the wax samples versus the square root of time. Diffusion coefficients of the two ${ }^{14} \mathrm{C}$-labelled compounds could be calculated from the slopes of regression lines fitted to linearised desorption kinetics applying eqn 
$(2)::^{25}$

$$
\frac{M_{\mathrm{t}}}{M_{\mathrm{o}}}=\frac{4}{\Delta x} \cdot \sqrt{\frac{D}{\pi}} \cdot \sqrt{t}
$$

$M_{\mathrm{t}} / M_{\mathrm{o}}$ is the relative amount desorbed, $\Delta x(\mathrm{~m})$ is the thickness of the wax layer, $D\left(\mathrm{~m}^{2} \mathrm{~s}^{-1}\right)$ is the diffusion coefficient and $t(\mathrm{~s})$ is the time. Rearranging the term $(4 / \Delta x) \sqrt{D / \pi}$, which is proportional to the slope of the regression line, finally allows the calculation of the molecular diffusion coefficient $(D)$ of the respective ${ }^{14} \mathrm{C}$ labelled compound in the wax sample.

The effects of different alcohol ethoxylates on desorption kinetics of PCP and $\mathrm{C}_{24} \mathrm{AC}$ were measured using aqueous solutions of the surfactants as desorption media instead of borate buffer. Concentrations of the alcohol ethoxylates were always well above their CMC (three- to 25-fold), which kept the concentration of the monomers in the desorption medium constant during the course of the experiment. Calculated effects were the ratio of the diffusion coefficients, obtained using solutions of alcohol ethoxylates as external desorption media, divided by diffusion coefficients measured using borate buffer as external desorption medium.

\subsection{Electron spin resonance studies}

The spin probe 5-SASL was added to the wax/ chloroform solution at a concentration of $1 \mathrm{mg} \mathrm{g}^{-1}$ wax. For the investigation of the effects of the different alcohol ethoxylates, the concentration of each single alcohol ethoxylate, which had been measured by GCanalysis to be the maximum possible amount of surfactant sorbed to the wax above the CMC, was added separately to the wax/5-SASL mixture in chloroform. The solvent of the wax samples prepared in this way was evaporated under a gentle stream of nitrogen. Remaining wax crystals were transferred to glass tubes (inner diameter: $1 \mathrm{~mm}$ ), which were sealed after the addition of the wax sample, melting the opening of the glass tube. ESR spectra were recorded on a Varian E-line ESR-spectrometer (Varian, Palo Alto, USA) at every $10^{\circ} \mathrm{C}$, covering a temperature range from $-10^{\circ} \mathrm{C}$ to a maximum of $60^{\circ} \mathrm{C}$. At each temperature three spectra were recorded and averaged.

\subsection{Statistics}

Results, measuring sorption of different alcohol ethoxylates to wax, are based on three replicates. Diffusion coefficients of each of the two compounds and each different desorption medium are based on five replicates. Results in the tables and the figures are given as means with $95 \%$ confidence intervals, unless stated otherwise.

\section{RESULTS}

Maximum equilibrium concentration of alcohol ethoxylates dissolved in barley wax decreased by a factor of about 6 from $48.7 \mathrm{mmol} \mathrm{kg}^{-1}$ for $\mathrm{C}_{4} \mathrm{E}_{2}$ to $8.4 \mathrm{mmol} \mathrm{kg}^{-1}$ for $\mathrm{C}_{16} \mathrm{E}_{8}$ (Table 2). Calculated wax/ water partition coefficients $\left(K_{\mathrm{ww}}\right)$ ranged over more than five orders of magnitude from 0.083 for $C_{4} E_{2}$ to 12350 for $\mathrm{C}_{16} \mathrm{E}_{8}$ (Table 2). On average, $K_{\mathrm{ww}}$ values, which were strongly correlated to cuticle/water partition coefficients $\left(K_{\mathrm{cw}}\right)$, were about one order of magnitude lower than $K_{\mathrm{cw}}$ values of the respective alcohol ethoxylates (Fig. 1).

The effects of the respective alcohol ethoxylates on the mobilities of PCP and $\mathrm{C}_{24} \mathrm{AC}$ in reconstituted barley wax reached maxima in the range $\mathrm{C}_{6} \mathrm{E}_{3}$ to

TABLE 2

Critical Micelle Concentrations (CMC), Cuticle/Water Partition Coefficients $\left(K_{\mathrm{cw}}\right)$, Equilibrium Concentrations in Barley Wax (CONC) and Calculated Wax/Water Partition Coefficients $\left(K_{\mathrm{ww}}\right)$ of the Alcohol Ethoxylates Investigated in This Study

\begin{tabular}{|c|c|c|c|c|}
\hline Compound & $\begin{array}{c}C M C^{a} \\
\left(m m o l k g^{-1}\right)\end{array}$ & $K_{c w}{ }^{a}$ & $\begin{array}{c}\operatorname{CONC} \mathrm{C}^{\mathrm{b} c} \\
\left(\mathrm{mmol} \mathrm{kg}^{-1}\right)\end{array}$ & $K_{w w}{ }^{c}$ \\
\hline $\mathrm{C}_{4} \mathrm{E}_{2}$ & 589 & 0.912 & $48 \cdot 7 \pm 4 \cdot 3$ & $0.083( \pm 0.0073)$ \\
\hline $\mathrm{C}_{6} \mathrm{E}_{3}$ & 60 & $6 \cdot 76$ & $49 \cdot 9 \pm 9 \cdot 7$ & $0.83( \pm 0.16)$ \\
\hline $\mathrm{C}_{8} \mathrm{E}_{4}$ & $6 \cdot 2$ & $50 \cdot 11$ & $30 \cdot 3 \pm 4.9$ & $4.9( \pm 0.79)$ \\
\hline $\mathrm{C}_{10} \mathrm{E}_{5}$ & 0.63 & 372 & $22 \cdot 5 \pm 3 \cdot 4$ & $35 \cdot 7( \pm 5.4)$ \\
\hline $\mathrm{C}_{12} \mathrm{E}_{6}$ & 0.065 & 2754 & $13 \cdot 1 \pm 2 \cdot 4$ & $201( \pm 37)$ \\
\hline $\mathrm{C}_{12} \mathrm{E}_{8}$ & 0.098 & 1259 & $10 \cdot 2 \pm 2 \cdot 6$ & $104( \pm 27)$ \\
\hline $\mathrm{C}_{14} \mathrm{E}_{7}$ & 0.0066 & 20417 & $10 \cdot 3 \pm 2 \cdot 9$ & $1561( \pm 439)$ \\
\hline $\mathrm{C}_{16} \mathrm{E}_{8}$ & 0.00068 & 151356 & $8 \cdot 4 \pm 1 \cdot 3$ & $12350( \pm 1910)$ \\
\hline
\end{tabular}

- Values are calculated from prediction equations published in Riederer et al. ${ }^{23}$

${ }^{b}$ External aqueous concentrations of the alcohol ethoxylates were between 3 and 25 times the concentrations of the respective CMCs.

${ }^{c}$ Values are $\pm 95 \%$ confidence intervals. 


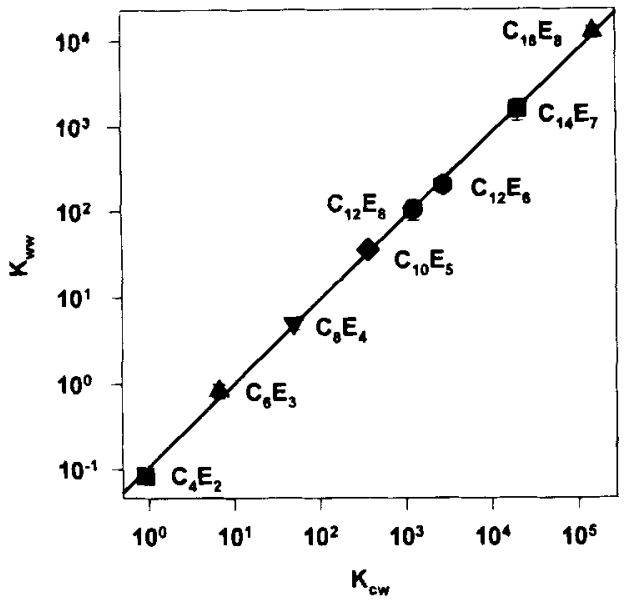

Fig. 1. Wax/water partition coefficients $\left(K_{\mathrm{ww}}\right)$ calculated from the maximum amount of alcohol ethoxylates sorbed in the wax and the critical micelle concentration (CMC) as a function of estimated cuticle/water partition coefficients $\left(K_{\mathrm{cw}}\right)$. $\mathrm{CMC}$ and $K_{\mathrm{cw}}$ values were obtained from Riederer et al. ${ }^{23}$ The parameters of the linear regression equation were: $\log$ $K_{\mathrm{ww}}=0.97 \times \log K_{\mathrm{cw}}-0.98\left(r^{2}=0.999\right)$.

$\mathrm{C}_{10} \mathrm{E}_{5}$. Effects on PCP mobility ranged from a $3 \cdot 3$-fold increase of $D$ in the presence of $C_{14} E_{7}$ to a 19.6-fold increase of $D$ with $\mathrm{C}_{6} \mathrm{E}_{3}$. With $\mathrm{C}_{24} \mathrm{AC}$, however, effects of the same alcohol ethoxylates on $D$ were about one

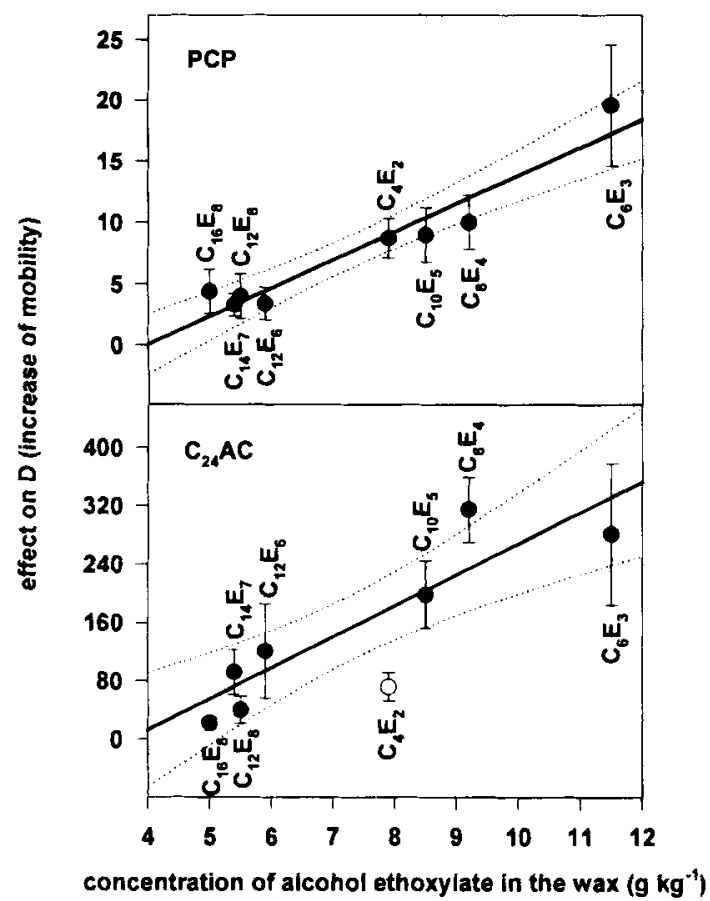

Fig. 2. Effects of alcohol ethoxylates on mobilities of pentachlorophenol (PCP) and tetracosanoic acid $\left(\mathrm{C}_{24} \mathrm{AC}\right)$ in reconstituted wax of Hordeum vulgare $\mathrm{L}$. as a function of the maximum equilibrium concentration of the alcohol ethoxylates in barley wax. Parameters of the linear regression equations with each of the compounds were: (1) PCP: effect $=2.29 \times$ maximum concentration in wax -9.08 $\left(r^{2}=0.92\right)$; (2) $\mathrm{C}_{24} \mathrm{AC}$ : effect $=42.7 \times$ maximum concentration in wax $-158\left(r^{2}=0.84\right)$.
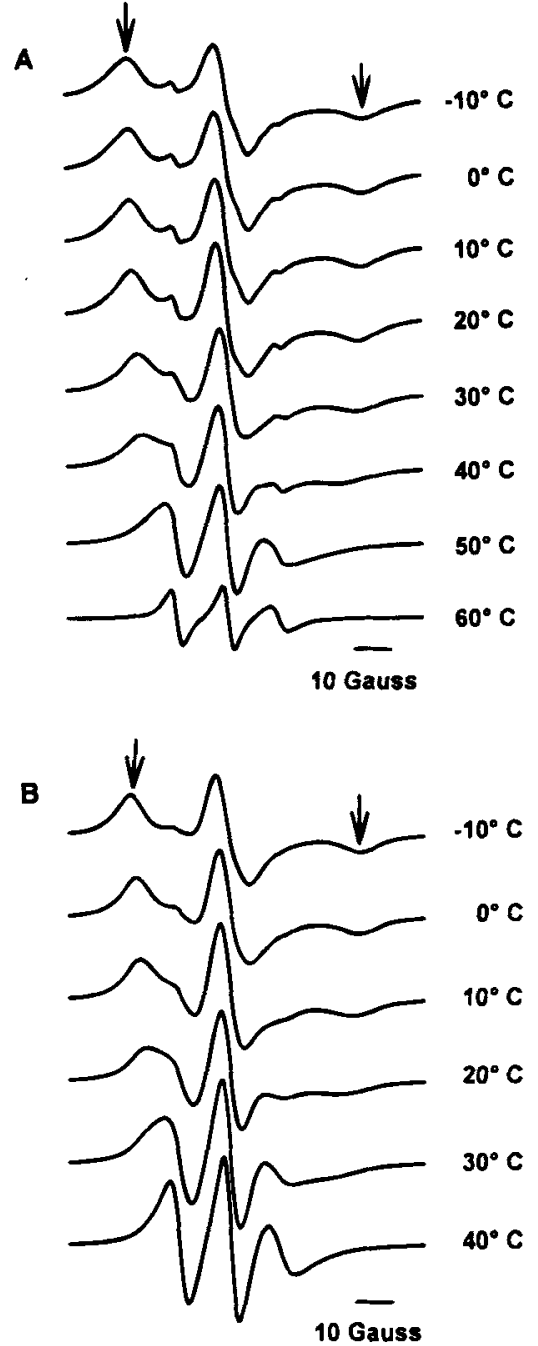

Fig. 3. Electron-spin resonance spectra of the spin label 5-doxyl stearic acid as a function of temperature in (A) pure wax of Hordeum vulgare $\mathrm{L}$. and $(\mathrm{B})$ in the presence of the alcohol ethoxylate triethylene glycol monododecyl ether $\left(\mathrm{C}_{6} \mathrm{E}_{3}\right)$. Arrows on the left and right side of the spectra mark the limitations of the hyperfine splitting $2 \mathrm{~A}_{\max }$. The total scan range was 100 gauss.

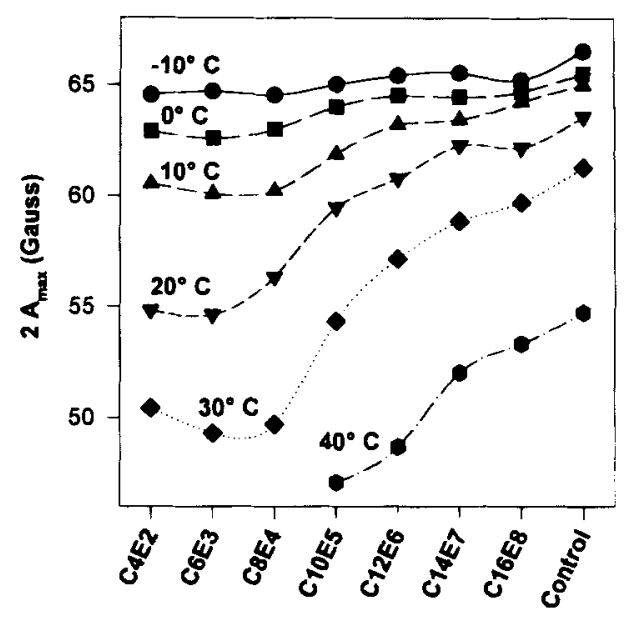

Fig. 4. The outer hyperfine splitting $2 A_{\max }$ of the spin label 5-doxyl stearic acid at different temperatures as a function of the investigated alcohol ethoxylates. 
order of magnitude larger, ranging from 22 -fold with $C_{16} E_{8}$ to 315 -fold with $C_{8} E_{4}$. Plotting the effects of the respective alcohol ethoxylates on the mobilities of the two compounds PCP and $\mathrm{C}_{24} \mathrm{AC}$ as a function of the maximum equilibrium concentrations in the wax shows good linear correlations (Fig. 2).

At low temperatures, ESR spectra of both pure wax (Fig. 3A) and wax containing a defined amount of an alcohol ethoxylate (here $\mathrm{C}_{6} \mathrm{E}_{3}$; Fig. 3B) showed the typical appearance for a sample in the solid phase. The pronounced hyperfine splitting in the outer regions of the spectra indicated a strong restriction of the mobility of the spin probe. With increasing temperatures hyperfine splitting constantly moved from both sides towards the centre of the spectrum finally disappearing completely (Fig. 3). Plotting the outer hyperfine splitting at each temperature as a function of the respective alcohol ethoxylate, a characteristic distribution was obtained (Fig. 4). Samples containing alcohol ethoxylates of intermediate size showed most rapid decrease in the size of the hyperfine splitting, whereas samples with the smallest and the larger alcohol ethoxylates showed a significantly slower decrease in the $2 \mathrm{~A}_{\max }$ values (Fig. 4).

\section{DISCUSSION}

Experiments carried out in this study are based on the hypothesis that the observed increase of cuticular permeability in the presence of surfactants is due to a direct interaction of the surfactants with the waxy transport barrier of the cuticle. Results of several investigations recently, dealing with the effects of monodisperse alcohol ethoxylates on the permeability of isolated cuticular membranes, ${ }^{21,22}$ on the sorption of monodisperse alcohol ethoxylates to cuticular membranes, ${ }^{23}$ and on the interaction of a single alcohol ethoxylate with isolated cuticular wax, ${ }^{12}$ strongly suggested this interpretation. In order to analyse this hypothesis, the following information had to be obtained: (i) what are the maximum equilibrium concentrations of monodisperse alcohol ethoxylates in cuticular wax in contact with an aqueous solution, (ii) to what extent are the mobilities of organic compounds in reconstituted cuticular wax increased by alcohol ethoxylates and is this a function of the concentration of surfactant in the wax and (iii) in which way do surfactants interact with cuticular wax leading to decreased barrier properties? Thus, the following discussion will deal with these three questions and try to find answers to them.

\subsection{Sorption of alcohol ethoxylates in wax}

As shown recently, investigating the sorption of alcohol ethoxylates by isolated cuticular membranes ${ }^{23}$ and the sorption of a single alcohol ethoxylate by isolated cuticular wax, ${ }^{12}$ the maximum amount of a surfactant that can be sorbed from aqueous solutions is limited by the CMC. This is due to the fact that it is solely the concentration of the monomers, remaining more or less constant above the $\mathrm{CMC},{ }^{26}$ which forms the driving force for equilibrium sorption to cutin or wax. Since the CMC of the investigated surfactants significantly decreases with increasing size of the alcohol ethoxylates, the maximum concentration in the wax decreases from $\mathrm{C}_{4} \mathrm{E}_{2}$ to $\mathrm{C}_{16} \mathrm{E}_{8}$ (Table 2). Furthermore, as the concentration of monomers in the aqueous solution stays essentially constant above the $\mathrm{CMC}, K_{\mathrm{ww}}$ can easily be estimated as the quotient of maximum concentration in the wax and the CMC (Table 2).

Results obtained here with isolated wax of barley leaves show that equilibrium sorption of the alcohol ethoxylates to cuticular wax $\left(K_{\mathrm{ww}}\right)$ is about the one order of magnitude lower than equilibrium sorption of the respective compounds to cutin $\left(K_{\mathrm{cw}}\right)$ (Table 2 and Fig. 1). This is in good accordance with results obtained recently comparing the sorption of various pesticides to isolated wax of barley ${ }^{27}$ and of different conifer species $^{28}$ with sorption to isolated cuticles. In order to avoid confusion it should be mentioned that the $K_{\mathrm{ww}}$ of $C_{12} E_{8}$ measured here $(104( \pm 27))$ is about $50 \%$ lower than the value reported in a recent investigation $(197( \pm 77))$. However, the two values are statistically not different at the $95 \%$ level. ${ }^{12}$

Concerning the mechanisms of sorption either to wax or to cutin, no fundamental differences should be expected. Lipophilic organic chemicals like pesticides and amphiphilic surfactants like the alcohol ethoxylates do not seem to behave differently. The fact that $K_{\mathrm{ww}}$ was always about one order of magnitude lower than $K_{\mathrm{cw}}$ can be attributed to the physically different structures of wax and cutin. Wax, which is composed of amorphous and highly ordered, crystalline phases, ${ }^{7,8}$ evidently offers significantly fewer sorption sites than the amorphous cutin polymer.

\subsection{Effects of alcohol ethoxylates on mobilities of organic compounds in wax}

The distribution of the effects obtained with PCP and $\mathrm{C}_{24} \mathrm{AC}$ and isolated wax are very similar to those which have been obtained recently with 2,4-D and isolated cuticular membranes. ${ }^{21}$ Furthermore, in contrast to $\mathrm{C}_{24} \mathrm{AC}$, which is a linear long-chain aliphatic molecule, absolute values of the effects for the two comparable compounds PCP and 2,4-D, which are both chlorinated, aromatic pesticide molecules, are similar, even though they have been obtained using two different experimental systems. Thus, effects of the alcohol ethoxylates, as measured with isolated cuticles, can also be observed using isolated cuticular wax. From this com- 
parison it may be concluded that it is justified to analyse the mechanisms of cuticular transport applying this artificial model of reconstituted cuticular wax, which forms the transport-limiting barrier of the intact plant cuticle. However, despite the good accordance between isolated wax and intact cuticles found in this study, it should be pointed out that wax/cutin interfaces may also be of some importance in cuticular transport, and cannot be studied applying this artificial experimental system.

Some alcohol ethoxylate homologues, especially those of intermediate size, are more effective than others. Plotting the maximum equilibrium concentration of alcohol ethoxylates in the wax as a function of their effects shows good correlations (Fig. 2), indicating unspecific wax/surfactant interactions. Their magnitude should mainly depend on the concentration of surfactant in the wax. This has recently been suggested when correlating the concentration of the same alcohol ethoxylates sorbed in cutin with their effects on 2,4-D mobility in isolated cuticles. ${ }^{23}$ However, with $\mathrm{C}_{24} \mathrm{AC}$ (Fig. 2) and 2,4-D, ${ }^{21} \mathrm{C}_{4} \mathrm{E}_{2}$ did not fit into the correlations, since the amounts sorbed to the wax were far too high compared with the induced effects (Fig. 2). For 2,4-D this deviation can be explained by the fact that the aqueous concentration of $\mathrm{C}_{4} \mathrm{E}_{2}$ used in the desorption experiments was more than 20 times below the $\mathrm{CMC}$ of $\mathrm{C}_{4} \mathrm{E}_{2} \cdot 21$

\subsection{ESR-studies of surfactant/wax interactions}

The interaction of surfactants with the waxy transport barrier of cuticles has been studied using ESRspectroscopy. Since spin labels are not typical aliphatic molecules, due to their bulky and polar nitroxyl-group, they will be located in the amporphous wax phase.7,8 Thus they form an excellent label for the amorphous wax phase, where the diffusion of 'non-wax' molecules, such as pesticides, is supposed to take place. ${ }^{10}$ Several investigations dealing with similar questions concerning transport properties of different biological membranes, such as human skin, ${ }^{29}$ biomembranes of plants ${ }^{30}$ as well as plant cuticles, ${ }^{31}$ have recently utilised ESRspectroscopy.

Comparing the spectrum of pure wax with the spectrum of wax containing $\mathrm{C}_{6} \mathrm{E}_{3}$ at a concentration corresponding to the maximum concentration in the wax at $25^{\circ} \mathrm{C}$ above the $\mathrm{CMC}$, it is obvious that the surfactant significantly reduced the temperature at which the hyperfine splitting of the spectrum completely disappeared (Fig. 3). Whereas it is still detectable at $40^{\circ} \mathrm{C}$ with pure wax, it had vanished completely at $30^{\circ} \mathrm{C}$ when the wax sample contained the alcohol ethoxylate $\mathrm{C}_{6} \mathrm{E}_{3}$. This shows that a significant fraction of the spin probe is still in a rigid environment in the pure wax at $40^{\circ} \mathrm{C}$ (Fig. 3A), whereas in the presence of the $\mathrm{C}_{6} \mathrm{E}_{3}$, the spin probe is in a liquid environment, where it can freely rotate around its own axis (Fig. 3B).

When the hyperfine splitting $\left(2 \mathrm{~A}_{\max }\right)$ is plotted at equal temperatures as a function of the individual monomers (Fig. 4), the distribution of the decrease of the hyperfine splitting closely resembles the distribution of the effects of the respective alcohol ethoxylates. Thus, the different effects which are induced by the different surfactants on the mobilities of the investigated compounds are based on different degrees of fluidity of the wax environment where diffusion takes place. With those surfactants that reach higher concentrations in the wax, the wax barrier is obviously in a more fluid state at given temperature compared with other surfactants.

\subsection{Conclusion}

The investigations presented above were intended to help understand basic mechanisms governing the interaction of surfactants with plant waxes and to contribute to an improved design for the formulation of plantprotecting agents. In contrast to this study, which investigated a 'non-evaporating' system, the most important difference between our experimental system and the field situation will be that spray droplets evaporate. Thus, under real conditions, foliar uptake occurs from highly concentrated residues, consisting of the formulation components and the active ingredient. Surfactant effects will become independent of CMC and will be related to ratios of amounts of surfactants and wax and to surfactant mobility in waxes. ${ }^{32}$ This is a situation where other principles may be more important than the ones described here. Therefore, future work concerning the enhancement of foliar uptake by surfactants must include these more realistic aspects of evaporating spray droplets.

\section{ACKNOWLEDGEMENTS}

The authors thank Prof. Dr J. Schönherr and Dr P. Baur (Universität Hannover, Institut für Obstbau und Baumschule, Sarstedt, Germany) and Dr D. Marsh (Max-Planck-Institut für Biophysikalische Chemie, Abteilung Spektroskopie, Göttingen, Germany) for critically reviewing this manuscript. This investigation was partially supported by a grant from the Kernforschungsanlage Jülich $\mathrm{GmbH}$.

\section{REFERENCES}

1. Hull, H. M., Leaf structure as related to absorption of pesticides and other compounds. Resid. Rev., 31 (1970) 1-150. 
2. Martin, J. T. \& Juniper, B. E., The Cuticles of Plants. Arnolds, London, 1970.

3. Cutler, D. F., Alvin, K. L. \& Price, C. E., The Plant Cuticle. Academic Press, London, 1982.

4. Holloway, P. J., The chemical constitution of plant cutins. In The Plant Cuticle, ed. D. F. Cutler, K. L. Alvin and C. E. Price. Academic Press, London, 1982, pp. 45-85.

5. Baker, E. A., Chemistry and morphology of plant epicuticular waxes. In The Plant Cuticle, ed. D. F. Cutler, K. L. Alvin and C. E. Price. Academic Press, London, 1982, pp. 139-65.

6. Walton, T. J., Waxes, cutin and suberin. Meth. Plant Biochem., 4 (1990) 105-58.

7. Reynhardt, E. C. \& Riederer, M., Structure and molecular dynamics of the cuticular wax from leaves of Citrus aurantium L. J. Phys. D: Appl. Phys., 24 (1991) 478-86.

8. Reynhardt, E. C. \& Riederer, M., Structures and molecular dynamics of plant waxes. II Cuticular waxes from leaves of Fagus sylvatica L. and Hordeum vulgare L. Europ. Biophys. J., 23 (1994) 59-70.

9. Schönherr, J. \& Riederer, M., Foliar penetration and accumulation of organic chemicals in plant cuticles. Rev. Environ. Cont. Toxicol., 108 (1989) 1-70.

10. Riederer, M. \& Schreiber, L., Waxes: the transport barriers of plant cuticles. In Waxes: Chemistry, Molecular Biology and Functions, ed. R. J. Hamilton. The Oily Press, Dundee, 1995, pp. 131-56.

11. Schreiber, L. \& Schönherr, J., Mobilities of organic compounds in reconstituted cuticular wax of barley leaves: determination of diffusion coefficients. Pestic. Sci., 38 (1993) 353-61.

12. Schreiber, L., A mechanistic approach towards surfactant/ wax interactions: effects of octaethyleneglycolmonododecylether on sorption and diffusion of organic chemicals in reconstituted cuticular wax of barley leaves. Pestic. Sci., 45 (1995) $1-11$

13. Schreiber, L., Kirsch, T. \& Riederer, M., Transport properties of cuticular waxes of Fagus sylvatica L. and Picea abies (L.) Karst.: estimation of size selectivity and tortuosity from diffusion coefficients of aliphatic molecules. Planta, 198 (1995) 104-9.

14. Kirkwood, R. C., Use and mode of action of adjuvants for herbicides: a review of some current work. Pestic. Sci., 38 (1993) 93-102.

15. Schönherr, J., Riederer, M., Schreiber. L. \& Bauer, H., Foliar uptake of pesticides and its activation by adjuvants: theories and methods for optimization. In Pesticide Chemistry. Advances in International Research, Development and Legislation, ed. H. Frehse. Verlag Chemie Weinheim, Weinheim, New York, Basel, Cambridge, 1991, pp. 239-53.

16. Bukovac, M. J. \& Petracek, P. D., Characterizing pesticide and surfactant penetration with isolated plant cuticles. Pestic. Sci., 37 (1993) 179-94.

17. Stock, D., Holloway, P. J., Grayson, B. T. \& Whitehouse, P., Development of a predictive uptake model to rationalise selection of polyoxyethylene surfactant adjuvants for foliage-applied agrochemicals. Pestic. Sci., 37 (1993) 23345.
18. Stock, D. \& Holloway, P. J., Possible mechanisms for surfactant-induced foliar uptake of agrochemicals. Pestic. Sci., 38 (1993) 165-77.

19. Coret, J., Gambonnet, B., Brabet, F. \& Chamel, A. R., Diffusion of 3 ethoxylated octylphenols across isolated plant cuticles. Pestic. Sci., 38 (1993) 201-9.

20. Knoche, M. \& Bukovac, M. J., Studies on octylphenoxy surfactants. 11. Effect on NAA diffusion through the isolated tomato fruit cuticulat membrane. Pestic Sci., 38 (1993) 211-17.

21. Schönherr, J., Effects of monodisperse alcohol ethoxylates on mobility of 2,4-D in isolated plant cuticles. Pestic. Sci., 38 (1993) 155-64.

22. Schönherr, J., Effects of alcohols, glycols and monodisperse ethoxylated alcohols on mobility of $2,4-\mathrm{D}$ in isolated plant cuticles. Pestic. Sci., 39 (1993) 213-23.

23. Riederer, M., Burghardt, M., Mayer, S., Obermeier, H. \& Schönherr, J., Sorption of monodisperse alcohol ethoxylates and their effects on the mobility of 2,4-D in isolated plant cuticles. J. Agr. Food Chem., 43 (1995) 1067-75.

24. Büscher, K. E., Messung der Dichte, des spezifischen Volumens und der kubischen Ausdehnungskoeffizienten plastischer Massen mit Hilfe des Haake-Konsistometers. Erdöl und Kohle, 13 (1960) 102-6.

25. Felder, R. M. \& Huvard, G. S., Permeation, diffusion and sorption of gases and vapors. In Methods of Experimental Physics, Vol. 16, Polmers, Part C: Physical Properties, ed. L. Marton and C. Marton. Academic Press, New York, 1980 , pp. 343-6.

26. Schick, M. J., Nonionic Surfactants. Physical Chemistry. Marcel Dekker, New York, Basel, 1988.

27. Schreiber, L. \& Schönherr, J., Analysis of foliar uptake of pesticides in barley leaves: Role of epicuticular waxes and compartmentation. Pestic. Sci., 36 (1992) 213-21.

28. Schreiber, L. \& Schönherr, J., Uptake of two chlorinated chemicals in conifer needles: reversibility and compartmental analysis. New Phytol., 123 (1993) 743-8.

29. Gay, C. L., Murphy, T. M., Hadgraft, J., Kellaway, I. W., Evans, J. C. \& Rowlands, C. C., An electron spin resonance study of skin penetration enhancers. Int. J. Pharm., 49 (1989) 39-45.

30. Kluge, M., Kliemchen, A. \& Galla, H.-J., Temperature effects on crassulacean acid metabolism: EPR spectroscopic studies on the thermotropic phase behavior of the tonoplast membranes of Kalanchoe daigremontiana. Bot. Acta, 104 (1991) 355-60.

31. Wunderlich, A. P., Gaub, H., Marsh, D. \& Sackmann, E., Local motion and conformational changes in the cuticle of Clivia miniata Regel. A microfluorescence and spinlabel study. Planta, 181 (1990) 475-86.

32. Schönherr, J., \& Baur, P., Modelling penetration of plant cuticles by crop protecting agents (CPA) and effects of adjuvants on rates of penetration. Pestic. Sci., 42 (1994) 185-208.

33. Abraham, M. H. \& McGowan, J. C., The use of characteristic volumes to measure cavity terms in reversed phase liquid chromatography. Chromatographia, 23 (1987) 2436. 